Article

\title{
The Role of Water Glass in the Flotation Separation of Fine Fluorite from Fine Quartz
}

\author{
Guofan Zhang, Yawen Gao, Wei Chen * and Dezhi Liu \\ School of Mineral Processing and Bioengineering, Central South University, Changsha 410083, China; \\ zhangguofan2002@163.com (G.Z.); gaoyawencsu@163.com (Y.G.); liudezhi@csu.edu.cn (D.L.) \\ * Correspondence: csuchenwei@csu.edu.cn; Tel: +86-0731-8883-0913
}

Received: 8 August 2017; Accepted: 23 August 2017; Published: 28 August 2017

\begin{abstract}
Fluorite is the principal mineral of fluorine and usually coexists with quartz in deposits. The removal of fine quartz in fluorite concentrate is the main problem in fluorite flotation. In this study, the flotation tests on fluorite, quartz and a weight equivalent mixture (all less than $10 \mu \mathrm{m}$ ) using water glass (with different modulus) as depressants and sodium oleate as collector were conducted. The mechanism of fine quartz entering the fluorite concentrate was investigated through optional observations and rheology measurements on the flotation pulp. The particle interactions between fine fluorite and quartz under flotation-related conditions were analyzed through zeta potential measurements and DLVO calculations. The results revealed that there existed strong hetero-coagulation between fluorite and quartz particles in the flotation pulp, which could be the main reason for the quartz entering the fluorite concentrate in the flotation process. Water glass with higher modulus could eliminate the hetero-coagulation more totally but inevitably influences the flotability of fluorite.
\end{abstract}

Keywords: flotation; water glass modulus; hetero-coagulation; fluorite; quartz

\section{Introduction}

Fluorite is the principal mineral of fluorine and is mainly used for the production of hydrofluoric acid and as a flux in steel making. Fluorite usually coexists with calcite, quartz and other silicate minerals in deposits. By now, fluorite is mostly recovered from these gangue minerals by froth flotation, through which can produce fluorite concentrate with grade up to $99 \%$ (by weight). In fluorite flotation, fatty acids and their derivatives are used as collectors for fluorite [1,2]. The common opinion for the collecting mechanism is the chemisorption that derives from the chemical interactions between the exposed $\mathrm{Ca}^{2+}$ on fluorite surface and carboxyl (-COO-) in the collectors [3,4].

The major requirement for the flotation process is the removal of the large amount of quartz in the flotation feeds. For this purpose, depressants are often added to depress the flotation of quartz. Common depressants used in fluorite flotation are water glass, phosphate and some kind of colloid such as tannin and starch [5-7]. Of all published depressants, water glass is the most widely used one for its low cost and stable depressant effect.

Water glass is a soluble silicate $\left(\mathrm{K}_{2} \mathrm{O} \cdot n \mathrm{SiO}_{2}\right.$ or $\left.\mathrm{Na}_{2} \mathrm{O} \cdot n \mathrm{SiO}_{2}\right)$ that is manufactured by the reaction of alkali metal oxides $\left(\mathrm{K}_{2} \mathrm{O}\right.$ or $\left.\mathrm{Na}_{2} \mathrm{O}\right)$ and silicon dioxide $\left(\mathrm{SiO}_{2}\right)$ [8]. It is widely used in the mineral processing industries as dispersant or modifier. The molar ratio $(n)$ of silicon dioxide to alkali metal oxides, termed modulus, is an important parameter for water glass used in flotation plants [9]. The modulus has a direct effect on the properties of the water glass, such as solubility, viscosity, dispersion and depressant ability. It has been reported that when the modulus increases, the depression effect of water glass on silicate minerals will increase; however, the solubility of the water glass will decrease and in turn limits its utilization $[8,10]$. Water glass has long been the depressant for quartz 
and other silicate minerals in the flotation of oxide ores [11], salt-type ores [12] and sulphide ores [13], especially for the flotation of fluorite [7].

However, the flotation separation of fluorite from quartz using water glass is not so effective, as there is always a small amount of fine quartz (less than $10 \mu \mathrm{m}$ ) in the fluorite concentrate. The floated fine quartz in fluorite concentrate has been reported to be the result of metal ion activation on the fine quartz that defeats the depressant effect of the water glass [13-15]. It has been demonstrated that the entrained fine quartz is the froth entrainment, which may also be an important factor that entrains the fine quartz into the fluorite concentrate [16-18]. To date, little work has been conducted on the effect of the modulus of water glass on the flotation of fluorite and the existence of fine quartz in the fluorite concentrate.

In this study, the effect of water glass modulus $(n)$ on the separation of fine fluorite and quartz was studied. The flotation tests on the single minerals of fine fluorite and quartz (all less than $10 \mu \mathrm{m}$ ) as well as mixed minerals were conducted using water glass (WG) (with modulus ranging from 1.0 to 3.5) as depressant and sodium oleate $(\mathrm{NaOl})$ as collector. The effect of water glass modulus on the level of aggregation between fine fluorite and quartz was discussed with the zeta potential measurements, optical observation and rheology measurements. The particle interactions between the fine fluorite and quartz with treatment of different modulus were compared by the DLVO calculations, on which basis the mechanism of the fine quartz entering the fluorite concentrate was proposed.

\section{Materials and Methods}

\subsection{Materials and Regents}

The samples of fluorite and quartz were all acquired from Chenzhou, Hunan, China. Hand-selected crystals of the two minerals were crushed to $-1 \mathrm{~mm}$ in a laboratory roll crusher and then ground in a planetary mill to get $-10 \mu \mathrm{m}$ samples. A part of pure sample was further ground to $-2 \mu \mathrm{m}$ in agate mortar for Zeta potential measurements. Quantitative X-ray diffraction (XRD) analysis (Figure 1) of the samples confirmed purity of $99.56 \mathrm{wt} \%$ for fluorite and $97.46 \mathrm{wt} \%$ for quartz.

The particle cumulative size distributions of the above material samples were measured with a Malvern Mastersizer 2000 (Malvern Instruments Ltd, Worcestershire, UK), by light scattering. The measurement was performed using a very dilute suspension (about $0.1 \mathrm{wt} \%$ solids) conditioned with dispersants followed by $20 \mathrm{~s}$ of ultrasonic dispersion. The results are shown in Figure 2 . The $\mathrm{D}_{50}$ of the fluorite and quartz samples was all about $5 \mu \mathrm{m}$.

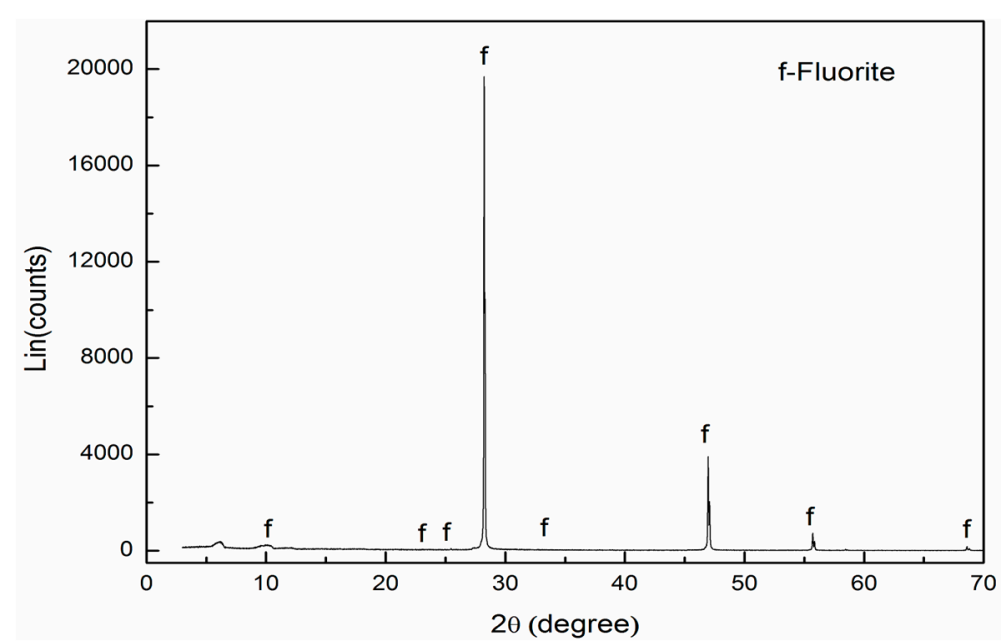

(a)

Figure 1. Cont. 


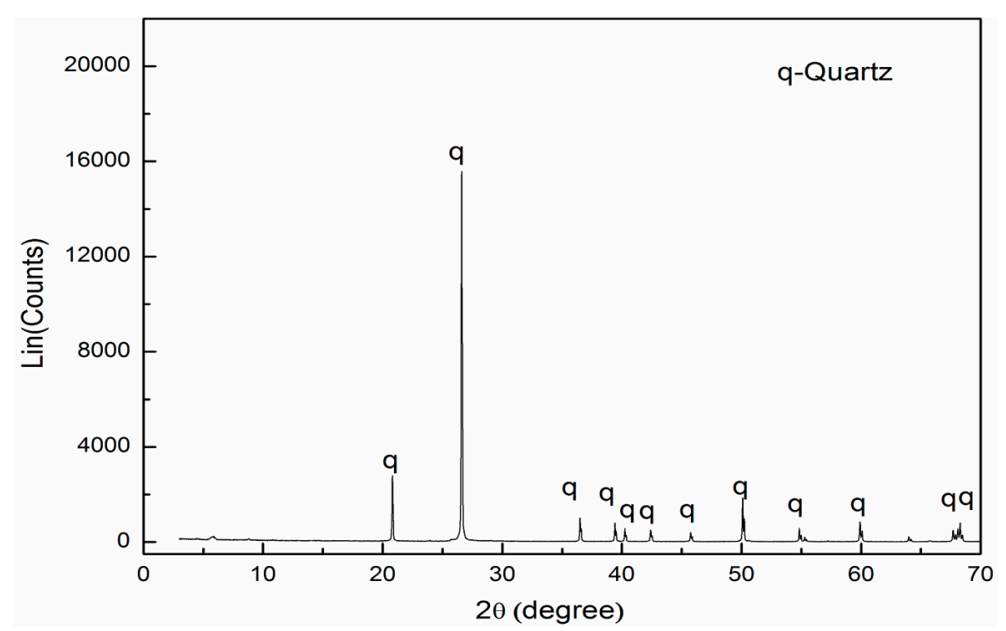

(b)

Figure 1. X-ray diffraction (XRD) spectrums of single fluorite (a) and quartz (b).

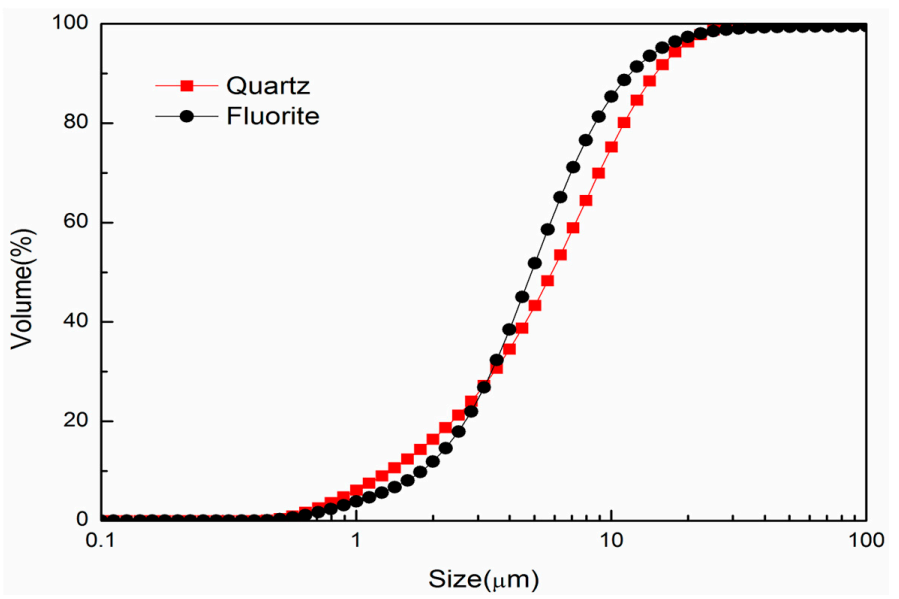

Figure 2. Particle cumulative size distributions of the fluorite and quartz samples.

Sodium oleate $\left(\mathrm{C}_{18} \mathrm{H}_{33} \mathrm{O}_{2} \mathrm{Na}\right)$ was used as collector for fluorite and was purchased from Tianjing Kermil Chemical Reagents Development Centre, Tianjin, China. Sodium hydroxide (NaOH) was used as $\mathrm{pH}$ regulator. All of the reagents were analytical pure. Water glass with different modulus was purchased from Changsha, China. The properties are listed in Table 1. Distilled water was used for all tests.

Table 1. Chemical composition and properties of water glass.

\begin{tabular}{cccccc}
\hline Modulus & $\mathbf{S i O}_{\mathbf{2}}$ & $\mathbf{N a}_{\mathbf{2}} \mathbf{O}$ & Solids (wt \%) & $\mathbf{H}_{\mathbf{2}} \mathbf{O}(\mathbf{w t} \mathbf{\%})$ & Viscosity $(\mathbf{m P a} \cdot \mathbf{s})$ \\
\hline 1.0 & 23.8 & 23.8 & 47.6 & 52.4 & 2.06 \\
1.5 & 23.04 & 15.36 & 38.4 & 61.6 & 4.62 \\
2.0 & 21.6 & 10.8 & 32.4 & 67.6 & 21.46 \\
2.5 & 28.93 & 11.57 & 40.5 & 59.5 & 127.57 \\
3.0 & 20.67 & 6.92 & 27.68 & 72.32 & 10.15 \\
3.5 & 27.9 & 8.1 & 34.6 & 65.4 & 75.16 \\
\hline
\end{tabular}

\subsection{Flotation Tests}

Micro-flotation tests were conducted on a XFGC type mechanical agitation flotation machine (Jilin exploration machinery factory, Changchun, China) with a $40 \mathrm{~mL}$ cell at $1800 \mathrm{rpm}$. For single 
mineral flotation test, mineral pulp was prepared by adding $2 \mathrm{~g}$ mineral samples to the cell with distilled water. $\mathrm{pH}$ was adjusted by $\mathrm{HCl}$ or $\mathrm{NaOH}$ solutions in 3 min. Depressant (if needed) and collector were added at a designed concentration. Conditioning time for each reagent was 3 min and flotation time was $4 \mathrm{~min}$ for each test. After flotation, the concentrate and tailing were collected, filtered, dried, weighed and the recovery was determined based on solid weight distributions between the two products. For artificial mixed minerals, mass ratio of fluorite and quartz was 1:1 for binary mixture ( $1 \mathrm{~g}$ fluorite $+1 \mathrm{~g}$ quartz). The concentrate and tailing were assayed for $\mathrm{Ca}$ and Si. Fluorite recovery was calculated based on $\mathrm{CaF}_{2}$ distributions between these products.

\subsection{Observations of Mineral Pulp}

The observation of mineral suspensions was conducted using a transmission light microscope (OLYMPUS-CX31RTSF, Olympus corporation, Tokyo, Japan). $1 \mathrm{~mL}$ of suspension was sampled by a syringe and diluted 10 times in a beaker by distilled water. Then, dilute solution was dropped on a microslide and was flatted by a coverslip on the objective table. Around $1000 \mu \mathrm{m} \times 1000 \mu \mathrm{m}$ region of slurry can be videoed by a digital camera, so the slurry images at any recorded time can be analyzed.

\subsection{Shear Yield Stress Measurements}

Shear yield stress is a measure of the resistance of the pulp to the permanent deformation in shear, or the minimum stress needed for the occurrence of flow. The yield stress of the flotation pulp is an indicative parameter of the particle interactions between different minerals. It has been proven to be the level of aggregation or dispersion in the mineral pulp [19,20].

The yield stress measurement was conducted with an Anton Paar MCR102 rheometer and a vane impeller probe. The sample holder is $38 \mathrm{~cm}^{3}$ and its diameter is $27 \mathrm{~mm}$. The impeller has 6 outer blades which diameter reaches $24 \mathrm{~mm}$. Each rheology measurement required a mineral pulp of $30 \mathrm{~mL}$ which was prepared through the conditioning operations in the flotation cell as stated in Section 2.2. The rheometer automatically set the distance between the base of the cup and the tip of the impeller which was $0 \mathrm{~mm}$ in this study. The shear stress range for the stress sweep was between $0.01 \mathrm{~Pa}$ and $20 \mathrm{~Pa}$ and it took around $9 \mathrm{~min}$ to cover the stress range. The measurement procedures involved the following steps: (1) pre-shearing of the slurry for $60 \mathrm{~s}$ at $300 \mathrm{~s}^{-1}$; (2) stabilization of the slurry for $15 \mathrm{~s}$ at $0 \mathrm{~s}^{-1}$; (3) measurement of shear strain with increasing shear stress. The yield stress was obtained from the shear stress vs. shear strain curves where the shear strain suddenly increased under increasing shear stress. It was calculated by the point where the tangent lines of the strain curves intersected.

\subsection{Zeta Potential Measurements}

Zeta potential measurements were conducted at $\mathrm{pH} 9.0$ and $25{ }^{\circ} \mathrm{C}$ on a Coulter Delsa440sx Zeta analyzer instrument using $1 \times 10^{-2} \mathrm{~mol} / \mathrm{L} \mathrm{KCl}$ as background electrolyte solution. Then, $0.03 \mathrm{~g}$ pure mineral sample $(-2 \mu \mathrm{m})$ was dispersed in $40 \mathrm{~mL}$ electrolyte solution using a magnetic stirrer with $\mathrm{HCl}$ and $\mathrm{NaOH}$ adjusting $\mathrm{pH}$. Flotation reagent was added at a desired concentration and conditioned for $10 \mathrm{~min}$. After a standing of $5 \mathrm{~min}$, the supernatant liquid was sucked out for measurement. At least three measurements were made for a certain experimental condition. The average value and the standard deviation were calculated.

\subsection{Particle Interaction Calculations-Derjguin-Landau-Verwey-Overbeek (DLVO) Theory}

According to the DLVO theory, the form and existence of particles depends on the combined action of Van-der-Waals force and electrostatic forces. Changes in the surface potential of particles can influence the electrostatic energy and further alter the aggregating state of mineral. On the basis of DLVO, the total interaction energy of particles in the liquid consisted of heterogeneous minerals can be calculated as

$$
V_{T}^{D}=V_{W}+V_{E}
$$


where $V_{W}$ is Van-der-Waals energy, J. $V_{E}$ means electrostatic energy, J. $V_{T}^{D}$ means the total interaction energy, $\mathrm{J}$. And $V_{W}$ is calculated as

$$
V_{W}=-\frac{A R_{1} R_{2}}{6 H\left(R_{1}+R_{2}\right)}
$$

where

$$
A=\left(\sqrt{A_{11}}-\sqrt{A_{33}}\right)\left(\sqrt{A_{22}}-\sqrt{A_{33}}\right)
$$

where $A$ means the Hammaker constant in vacuum. $H$ is the separation distance. For two different types of particles with radius $R_{1}$ and $R_{2}, V_{E}$ can be calculated as

$$
V_{E}=\frac{\pi \varepsilon_{a} R_{1} R_{2}}{R_{1}+R_{2}}\left(\psi_{01}^{2}+\psi_{02}^{2}\right)\left[\frac{2 \psi_{01} \psi_{02}}{\psi_{01}^{2}+\psi_{02}^{2}} p+q\right]
$$

where

$$
p=\ln \left(\frac{1+e^{-\kappa H}}{1-e^{-\kappa H}}\right)
$$

and

$$
q=\ln \left(1-e^{-2 \kappa H}\right)
$$

where $\mathrm{K}$ is the thickness of the electric double-layer, $\mathrm{K}=0.104 \mathrm{~nm}^{-1} ; \varepsilon_{a}$ is the relative dielectric constant of the continuous phase. $\varepsilon_{0}$ and $\varepsilon_{r}$ are the permittivity of free space and the relative permittivity, respectively $\left(\varepsilon_{\mathrm{a}}=\varepsilon_{0} \times \varepsilon_{\mathrm{r}}=6.95 \times 10^{-10} \mathrm{C}^{-2} \mathrm{~J}^{-1} \mathrm{~m}^{-1}\right) ; \psi_{0}$ means particle surface potential [21].

\section{Results and Discussion}

\subsection{Single Mineral Flotation Results}

The effect of pulp $\mathrm{pH}$ and $\mathrm{NaOl}$ dosage on the flotation behaviors of fine fluorite and quartz in the presence of $\mathrm{NaOl}$ alone was explored and the results are shown in Figure 3. The recovery of fluorite increased quickly with the dosage of $\mathrm{NaOl}$ but that of quartz seldom increased, as shown in Figure 3a. When $\mathrm{NaOl}$ dosage reached $5 \times 10^{-5} \mathrm{~mol} / \mathrm{L}$, the recoveries of fluorite and quartz was $86.56 \%$ and $4.32 \%$, respectively. The good collecting ability of $\mathrm{NaOl}$ towards fluorite derived from the chemisorption as stated in Section 1 . The collecting ability, or the chemisorption, has a large difference compared fluorite with quartz in tested $\mathrm{pH}$ range $7-12$ as in Figure $3 \mathrm{~b}$. The results indicated that, for single mineral pulp, using $\mathrm{NaOl}$ alone can achieve the separation of fluorite from quartz.

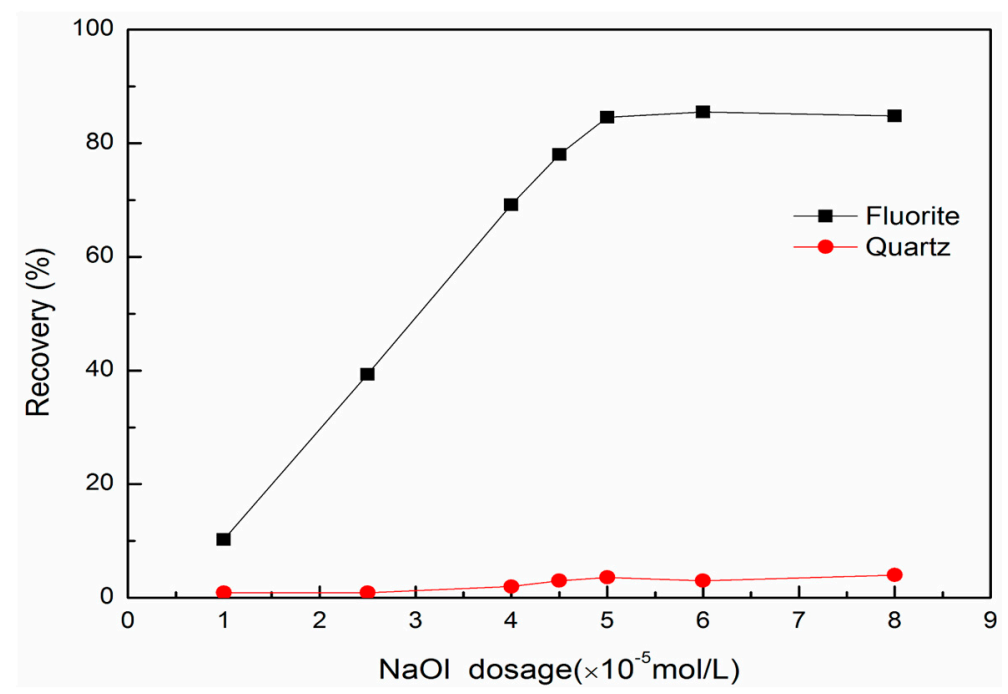

(a)

Figure 3. Cont. 


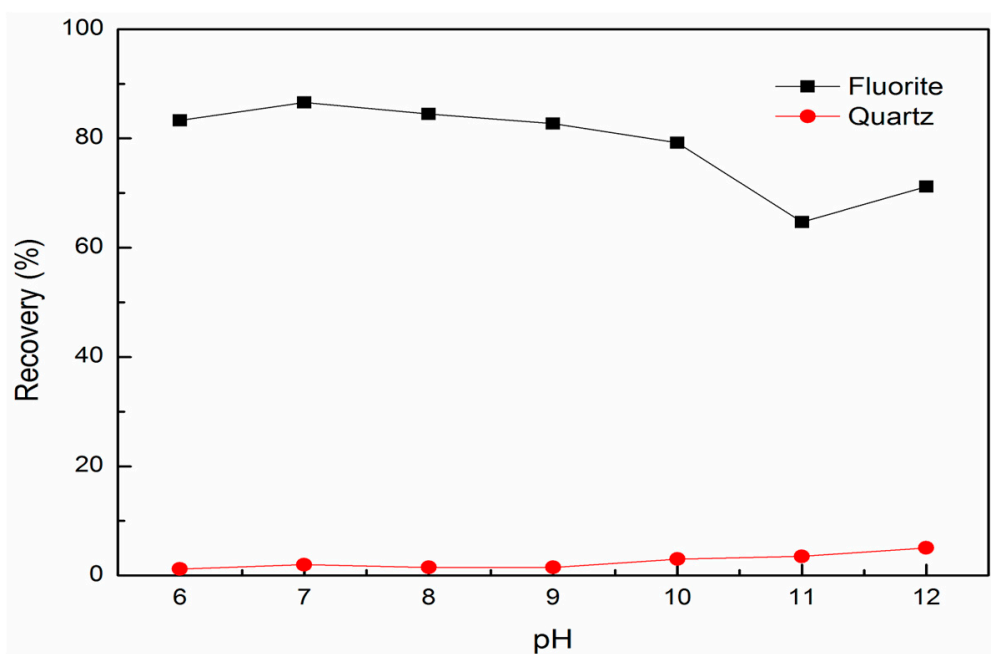

(b)

Figure 3. $\mathrm{NaOl}$ dosage (a) and effect of $\mathrm{pH}(\mathbf{b})$ on the flotation performance of fluorite and quartz in the absence of water glass (WG).

Figure 4 shows the flotation behaviors of fine fluorite and quartz in the presence of $\mathrm{WG}$ and $\mathrm{NaOl}$. It can be seen from Figure 4a that as WG $(n=2.5)$ dosage increased, the quartz kept unflotable and the flotation of fluorite was gradually depressed. The severe depression of fluorite was observed when WG dosage exceeded $15 \mathrm{mg} / \mathrm{L}$. Figure $4 \mathrm{~b}$ shows the flotability of fluorite in the presence of WG with different modulus with different $\mathrm{pH}$. It was first noted that the addition of WG exhibited a negative effect on fluorite flotation. As the WG modulus increased, the fluorite flotation was depressed more severely in the whole $\mathrm{pH}$ range. When the WG modulus was in the range of 1.0-2.5, the flotation of fluorite was similar with the results with no WG addition. When the modulus increased to 3.0-3.5, the fluorite flotation was significantly affected. The results demonstrated that the WG with higher modulus are not good for fluorite flotation.

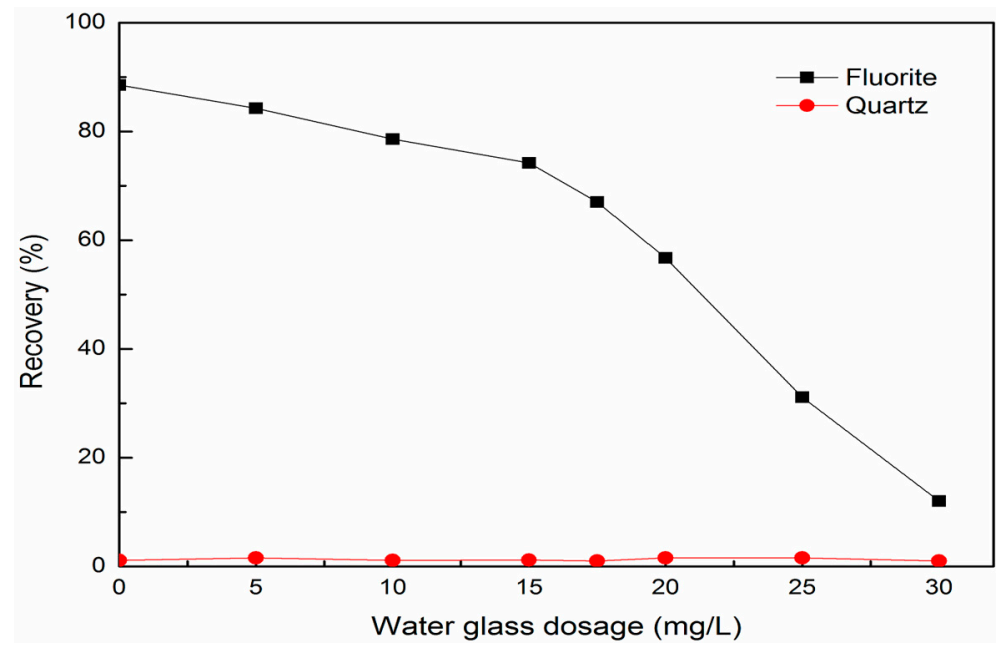

(a)

Figure 4. Cont. 


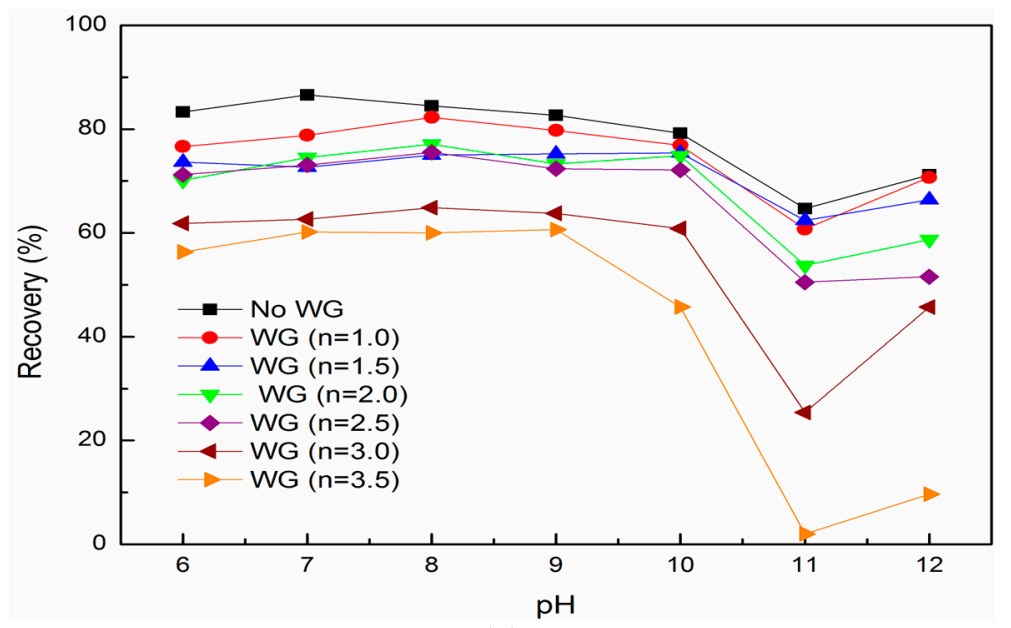

(b)

Figure 4. Effect of WG $(\mathrm{n}=2.5)$ dosage $(\mathbf{a})$ and $\mathrm{pH}(\mathbf{b})(c(\mathrm{WG})=15 \mathrm{mg} / \mathrm{L})$ on the flotation performance of fluorite $\left(c(\mathrm{NaOl})=5 \times 10^{-5} \mathrm{~mol} / \mathrm{L}\right)$.

\subsection{Mixed Binary Mineral Flotation Results}

From the single mineral flotation tests, adding water glass could recede the flotability of fluorite and has no effect on quartz, which is not beneficial to separate them for mixed binary minerals. However, it is simply not true. We usually add the water glass to separate fluorite and quartz ore in small scale tests or industrial tests. To explore this situation, we studied the flotation behavior of mixed binary minerals.

The fluorite and quartz were mixed at the mass ratio of 1:1 with addition of WG (with different modulus) at $15 \mathrm{mg} / \mathrm{L}$ and $\mathrm{NaOl}$ at $5 \times 10^{-5} \mathrm{~mol} / \mathrm{L}$, and the results achieved are shown in Table 2 . They showed that the grade of fluorite is $61.80 \%$ and its recovery is $79.12 \%$ in the absence of water glass. They showed that fluorite floated worse in the presence of the quartz than would have been expected from the results for the individual minerals. With the addition of WG, the concentration ratio increased as the WG modulus increased. When the modulus was 2.5, the grade of fluorite concentrate reached $73.56 \%$. The flotation results of the mixed binary minerals showed that the fine quartz also floated and got into the concentrate in the mixed mineral flotation. The results also indicated that addition of WG helped to promote the flotation separation of fluorite and quartz, and the WG with higher modulus exhibited better separation effect.

Table 2. Flotation results of mixed binary minerals (mass ratio 1:1).

\begin{tabular}{cccccccc}
\hline WG Modulus & No WG & $\boldsymbol{n = 1 . 0}$ & $\boldsymbol{n = 1 . 5}$ & $\boldsymbol{n = 2 . 0}$ & $\boldsymbol{n = 2 . 5}$ & $\boldsymbol{n = 3 . 0}$ & $\boldsymbol{n = 3 . 5}$ \\
\hline Fluorite grade (\%) & 61.80 & 65.12 & 68.40 & 70.08 & 73.56 & 77.01 & 79.10 \\
Fluorite recovery (\%) & 79.12 & 78.34 & 77.00 & 76.62 & 76.69 & 74.00 & 69.64 \\
Concentration ratio & 1.24 & 1.31 & 1.38 & 1.42 & 1.47 & 1.54 & 1.58 \\
\hline
\end{tabular}

\subsection{The Dispersion and Aggregation State of Mineral Particles in Pulp}

The optical observations on the mineral pulp in the absence and presence of flotation reagents were conducted and the results are shown in Figures 5 and 6. 

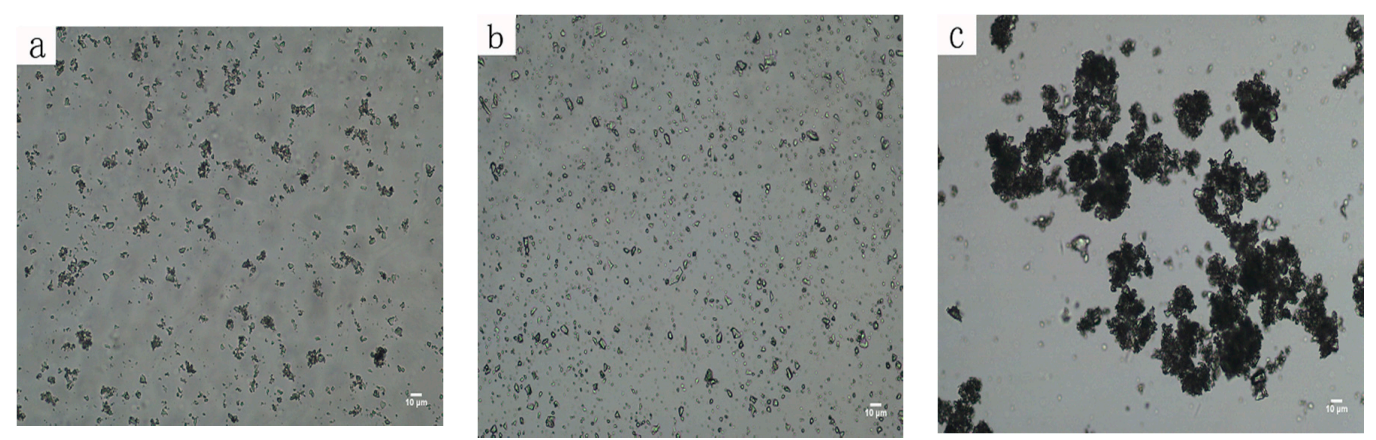

Figure 5. Dispersion and aggregation of fluorite (a), quartz (b), and mixed binary mineral (c) particles in distilled water.

Figure 5 shows the dispersion and aggregation state of fine fluorite, quartz and mixed binary mineral in the absence of any flotation reagents. For single mineral of fluorite and quartz shown in Figure $5 \mathrm{a}, \mathrm{b}$, the minerals were well dispersed. However, when fluorite and quartz were mixed in a weight equivalent proportion, a certain aggregation between the two minerals was observed as shown in Figure $5 c$. The observation results indicate a qualitative aggregation behavior in the mixed binary mineral pulp as well as in the flotation pup. This is consistent with the difference in the flotation results between the single minerals and mixed binary minerals. Therefore, it was the aggregation between fine fluorite and quartz that involved the fine quartz into the fluorite concentrate.
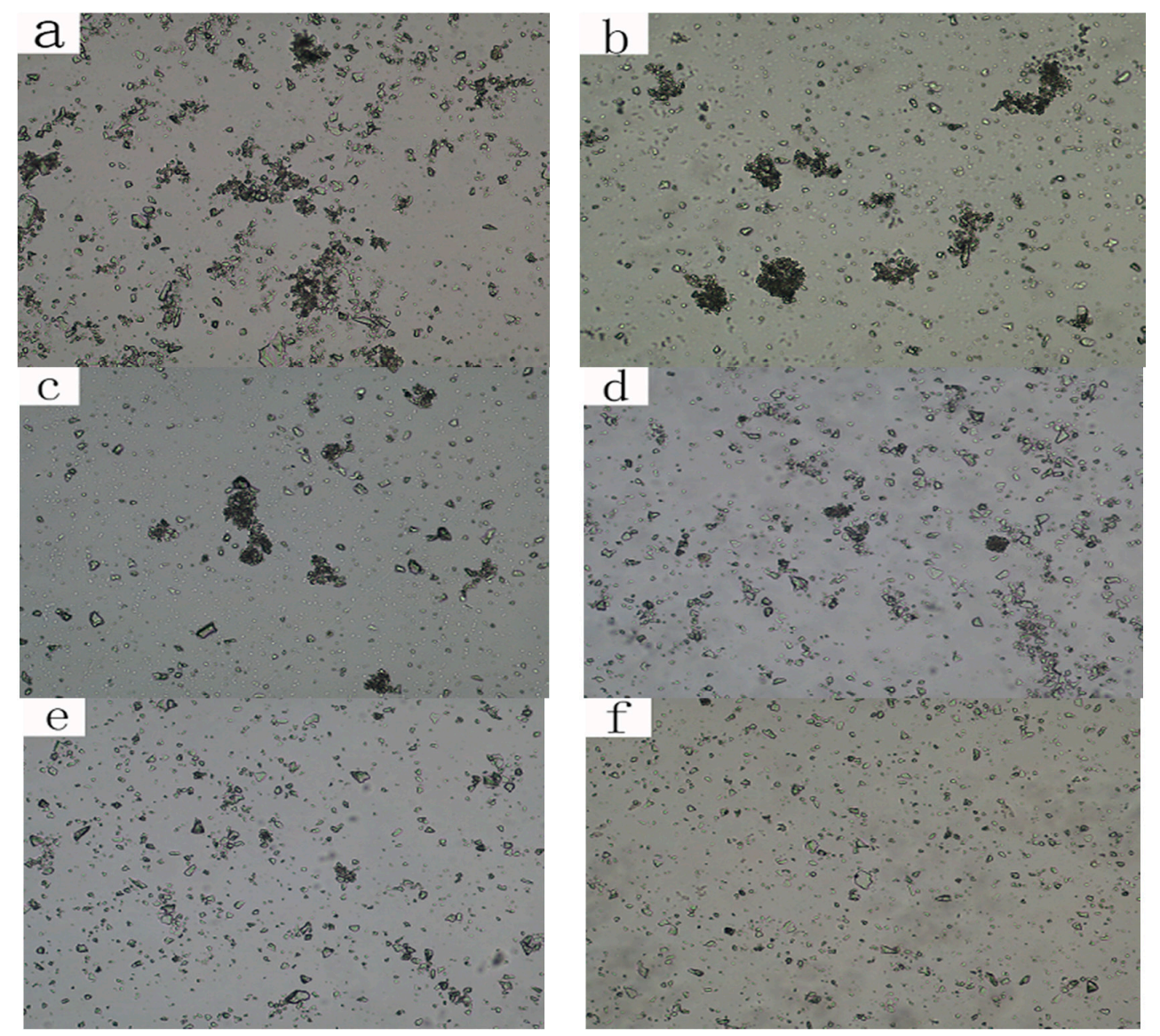

Figure 6. Dispersion and aggregation of mixed binary mineral in the presence of WG with different modulus: (a) $(n=1.0)$, (b) $(n=1.5),(\mathbf{c})(n=2.0),(\mathbf{d})(n=2.5),(\mathbf{e})(n=3.0)$ and $(\mathbf{f})(n=3.5)$ $(c(\mathrm{WG})=150 \mathrm{mg} / \mathrm{L}, c(\mathrm{NaOl})=300 \mathrm{mg} / \mathrm{L})$. 
Figure 6 presented a summary of the observations for the mixed binary mineral particle in the presence of WG with different modulus. The results showed that, as the WG modulus increased, the particles tended to get better dispersed. The aggregation, or the hetero-coagulation between fluorite and quartz, was eliminated more totally with WG with higher modulus. It should be noted that the elimination was beneficial for the flotation process, as can be seen from the flotation results in Table 2 .

\subsection{The Hetero-Coagulation between Fine Fluorite and Quartz in Pulp}

To quantify the hetero-coagulation between fine fluorite and quartz in the absence and presence of WG, the shear yield stress of pulp was measured. The results are shown in Figures 7 and $8 . \tau_{0}$ is shear yield stress; it also presents a necessary force that can break this system.

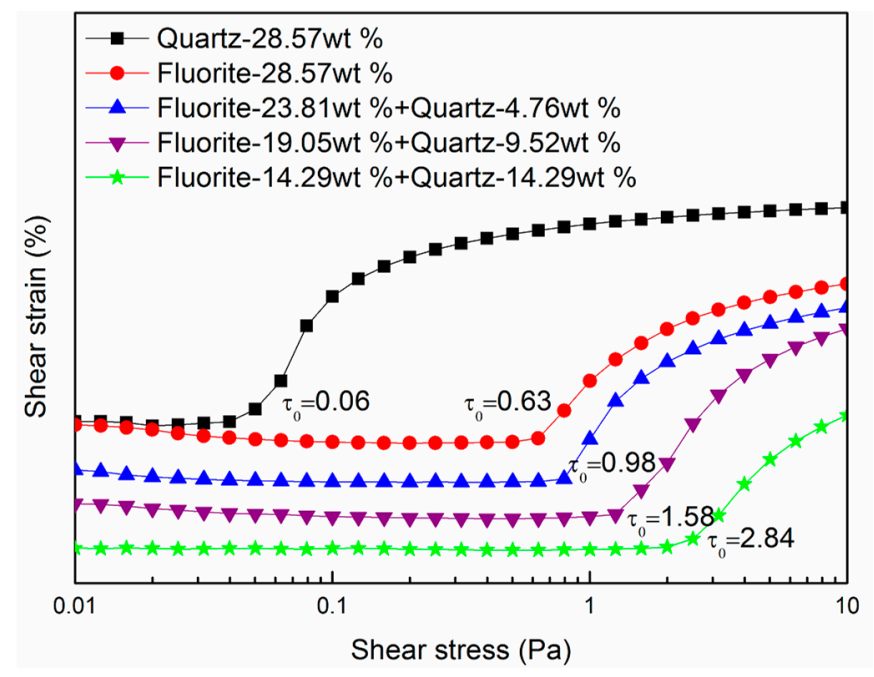

Figure 7. The shear strain-shear stress curves of quartz, fluorite and mixed mineral pulp in the absence of flotation reagents.

For single mineral pulp in Figure 7, the shear yield stress was $0.06 \mathrm{~Pa}$ for quartz and $0.63 \mathrm{~Pa}$ for fluorite. The results suggested a certain degree of aggregation in the single minerals pulp. However, for the mixed binary minerals, the shear yield stress did not locate in area of $0.06-0.63$ Pa but exceeded the range. It can be seen that as the proportion of fine quartz increased, the shear yield stress of the mixed binary mineral also increased. When fluorite and quartz were mixed in a weight equivalent proportion, the shear yield stress was high up to $2.84 \mathrm{~Pa}$, indicating that the aggregation level was higher than that in the single mineral pulp. The increased shear yield stress with fine quartz increasing in the pulp quantitatively demonstrated the strong hetero-coagulation between fine fluorite and quartz in flotation pulp.

The effect of WG modulus on the shear yield stress of the mixed binary mineral pulp was studied and the results are shown in Figure 8. As the WG modulus increased from 1.0 to 3.5, the shear yield stress of the 1:1 mixed binary minerals decreased from 2.84 to $0.71 \mathrm{~Pa}$, showing that the hetero-coagulation between the fluorite and quartz was weakened by the WG with higher modulus. Combining the effect of WG modulus on the flotation results in Table 2 with the quantitative hetero-coagulation result, it can be concluded that the WG with higher modulus helps to eliminate the hetero-coagulation between fluorite and quartz. This was also supported by the optical observations in Section 3.3. 


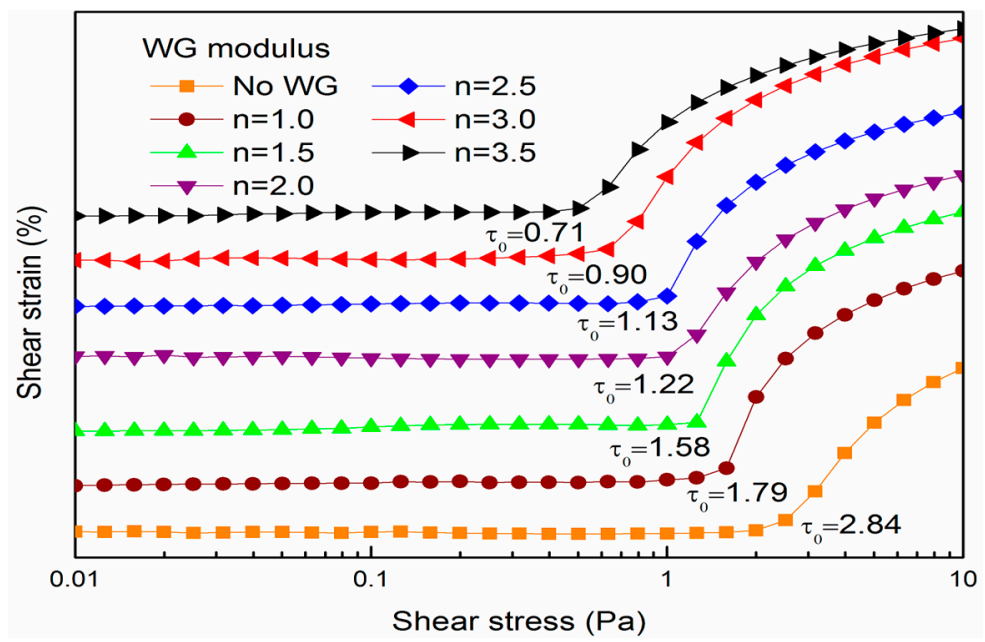

Figure 8. The shear strain-shear stress curves of mixed mineral (mass ratio of 1:1) pulp in the presence of WG (with different modulus) at $150 \mathrm{mg} / \mathrm{L}$.

\subsection{Surface Charge and Particle Interactions between Fluorite and Quartz}

In order to find out the mechanism of the hetero-coagulation, the particle interactions between fine fluorite and quartz were analyzed through zeta potential results and calculated using DLVO theory. The results are shown in Figures 9-14.

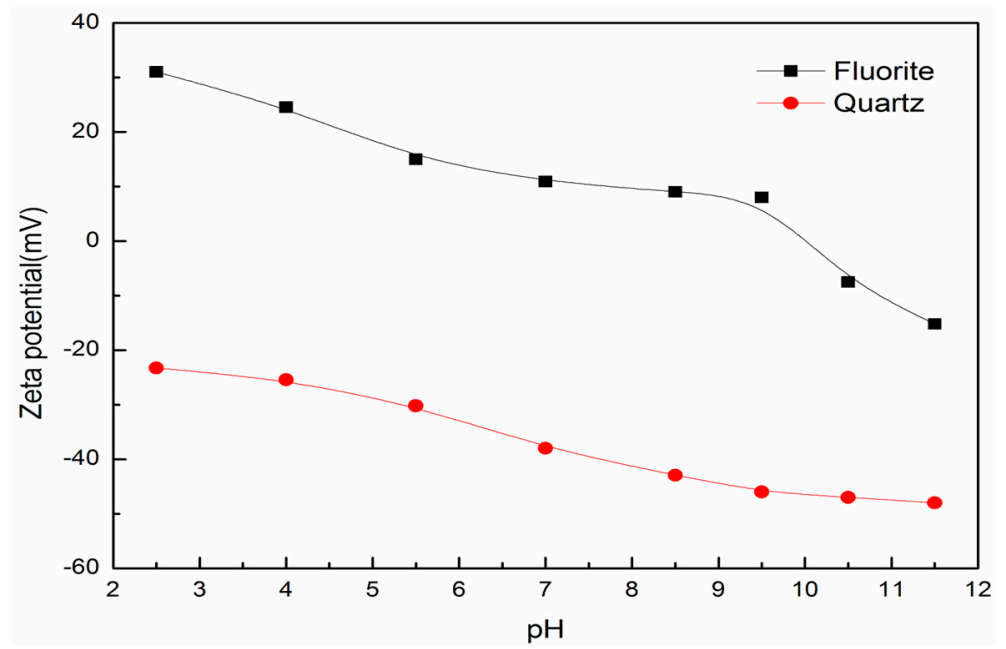

Figure 9. Zeta potential of fluorite and quartz under different $\mathrm{pH}$.

Figure 9 shows the zeta potential of fluorite and quartz under different $\mathrm{pH}$. Quartz was negatively charged across the $\mathrm{pH}$ range tested but fluorite was positively charged when $\mathrm{pH}$ was less than 10.0. Therefore, the electrostatic force between the two minerals when $\mathrm{pH}$ was less than 10 was attractive. It was easy to conclude that it is the attractive electrostatic force that contributed to the hetero-coagulation. The DLVO calculation results, including the Van der Waals' force and the electrostatic force, also confirmed the conclusion, as shown in Figure 10. In this calculation, the Hamaker constant $A_{11}$ of fluorite is $7.2 \times 10^{-20} \mathrm{~J}, \mathrm{~A}_{22}$ of quartz is $6.3 \times 10^{-20} \mathrm{~J}, \mathrm{~A}_{33}$ of water is $3.7 \times 10^{-20}$ J. $R_{1}$ and $R_{2}$ represent the radii of fluorite and quartz particle, respectively. $R_{1}$ and $R_{2}$ 
are $5 \mu \mathrm{m}$. The surface potential of fluorite $\psi_{01}$ is $0.01088 \mathrm{~V}$, and the quartz of surface potential $\psi_{02}$ is $-0.038 \mathrm{~V}$. The results are calculated as follows:

$$
V_{W}=-0.461 \times 10^{3} \times \frac{1}{H}
$$

$V_{E}$ equals

$$
V_{E}=2.07 \times 10^{3} \times\left[-0.529 \times \ln \frac{1+e^{-\kappa H}}{1-e^{-\kappa H}}+\ln \left(1-e^{-2 \kappa H}\right)\right]
$$

and

$$
V_{T}^{D}=-0.461 \times 10^{3} \times \frac{1}{H}+2.07 \times 10^{3} \times\left[-0.529 \times \ln \frac{1+e^{-\kappa H}}{1-e^{-\kappa H}}+\ln \left(1-e^{-2 \kappa H}\right)\right]
$$

It can be seen from Figure 10 that the value of $V_{W}, V_{E}$ and $V_{T}^{D}$ were always negative, suggesting the attractive interaction energy between fluorite and quartz particles. The calculations also indicated that it was the attractive interaction between the fluorite and quartz that causes the hetero-coagulation and then involved the fine quartz into the fluorite concentrate.

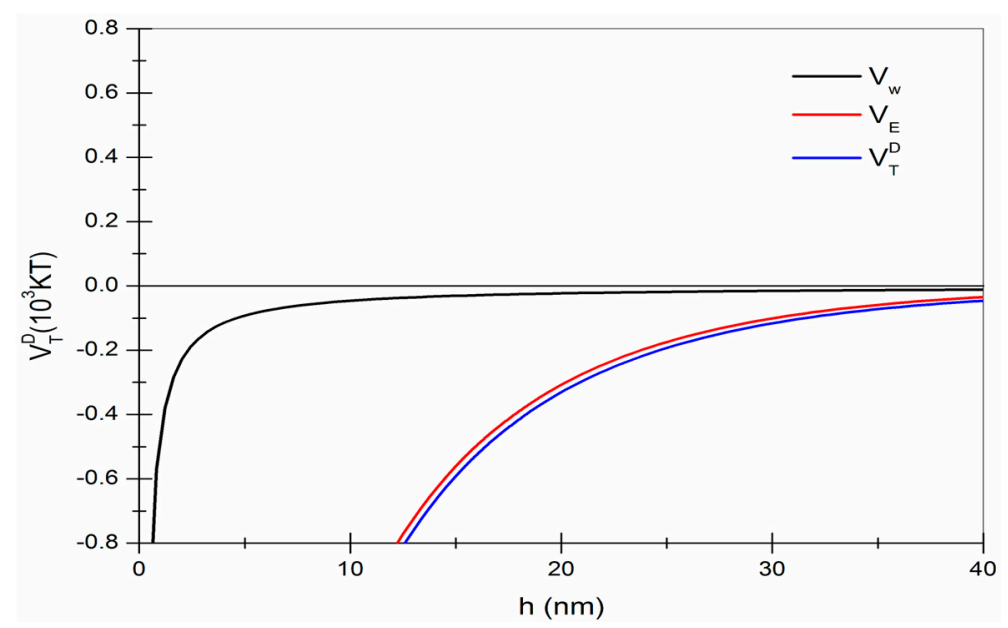

Figure 10. The relationship between interaction energy of fluorite and quartz and particles distance $(\mathrm{pH}=7)$.

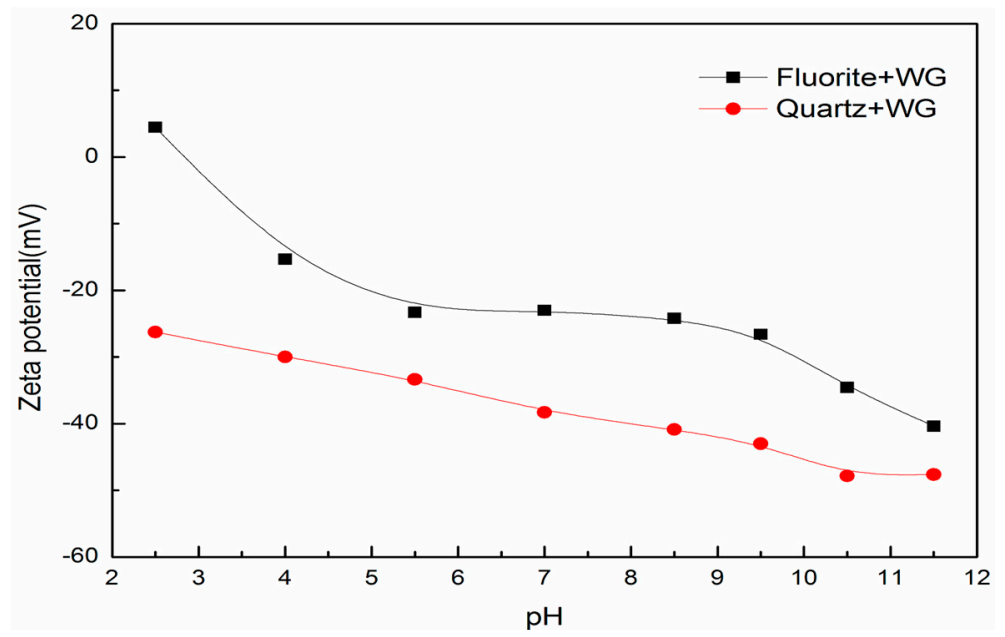

Figure 11. Zeta potential of fluorite and quartz with $W G$ under different $\mathrm{pH}\left(c(\mathrm{WG})=5 \times 10^{-5} \mathrm{~mol} / \mathrm{L}\right.$ $(n=2.5))$. 
Figure 11 shows the zeta potential of fluorite and quartz in the presence of WG under different $\mathrm{pH}$. Compared with the zeta potential results in Figure 9, the zeta potential of fluorite was remarkably decreased by the addition of WG. However, the change in zeta potential of quartz was insignificant. The results of $V_{W}, V_{E}$ and $V_{T}^{D}$ as a function of h when pulp $\mathrm{pH}$ was 7 were shown in Figure 12. The results indicated that with the addition of WG, the Van-der-Waals energy was still negative; however, the electrostatic energy changed to positive. As a result, an energy barrier $\left(2.22 \times 10^{-3} \mathrm{KT}\right)$ emerged, showing that the hetero-coagulation between fluorite and quartz could be hindered if the kinetic energy could not come over the barrier. The results showed that the addition of WG could help depress the hetero-coagulation between fluorite and quartz in flotation pulp.

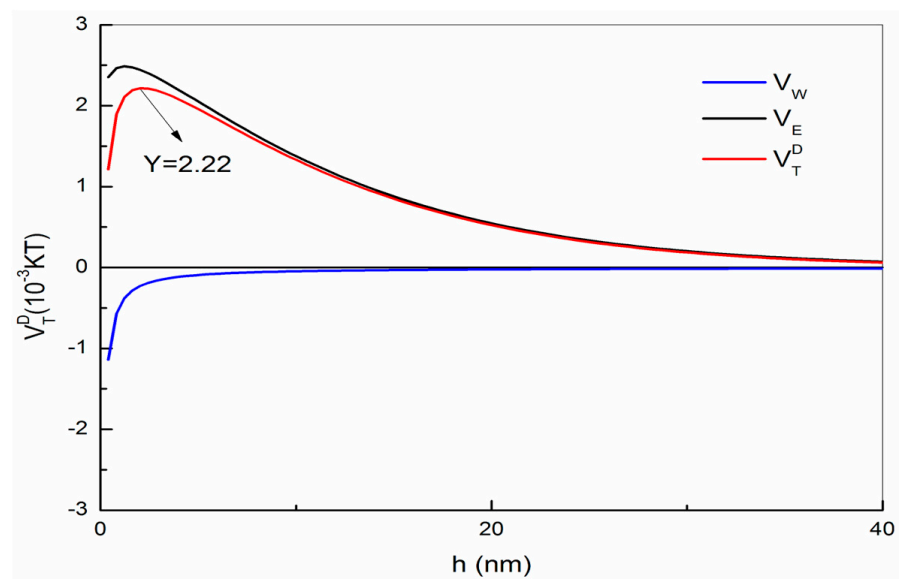

Figure 12. The interaction energy of fluorite and quartz particles with addition of WG ( $n=2.5$, $c(\mathrm{WG})=5 \times 10^{-5} \mathrm{~mol} / \mathrm{L}, \mathrm{pH}=7$ ) as a function of particle distance.

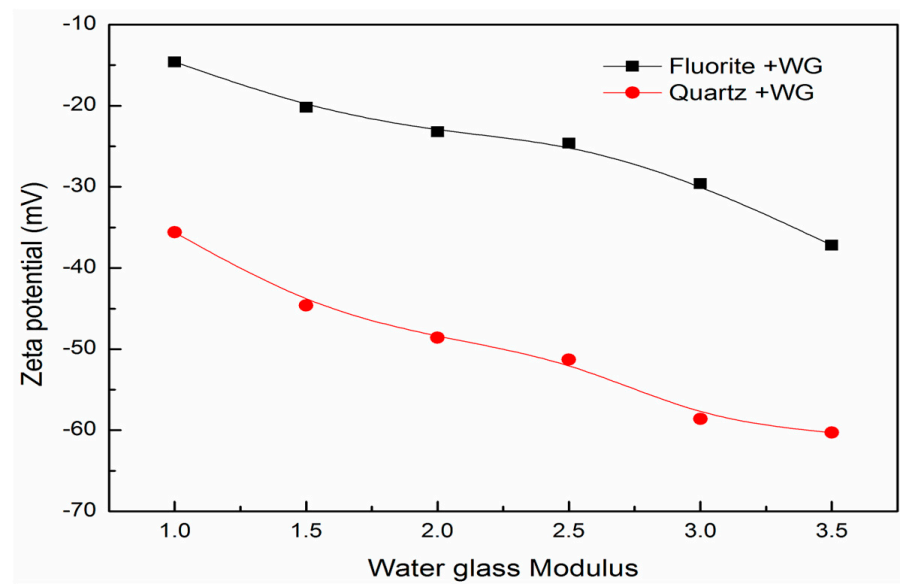

Figure 13. Zeta potential of fluorite and quartz with the addition of WG with different modulus $\left(c(\mathrm{WG})=5 \times 10^{-5} \mathrm{~mol} / \mathrm{L}\right)$.

The zeta potential of fluorite and quartz with the addition of WG with different modulus was measured and the results are shown in Figure 13. The results showed that as the modulus of WG increased, the surfaces of both minerals were more negatively charged. For fluorite, when the WG modulus was 1.0, the zeta potential was $-14.6 \mathrm{mV}$. When the WG modulus was 3.5 , the zeta potential was $-37.2 \mathrm{mV}$. For quartz, when the WG modulus was 1.0, the zeta potential was $-35.6 \mathrm{mV}$. When the WG modulus increased to 3.5 , the zeta potential increased to $-60.3 \mathrm{mV}$. The effect of the WG modulus on the interaction energy between the fluorite and quartz can be seen in Figure 14. As the WG modulus increased from 1.0 to 3.5, the energy barrier increased from $0.94 \times 10^{-3}$ to $6.11 \times 10^{-3} \mathrm{KT}$. 
The results demonstrate that the depression effect of the WG on the hetero-coagulation between fluorite and quartz was modulus dependent. WG with higher modulus exhibited more depression effect on the hetero-coagulation between fine fluorite and quartz and therefore, improved more on the flotation selectivity.

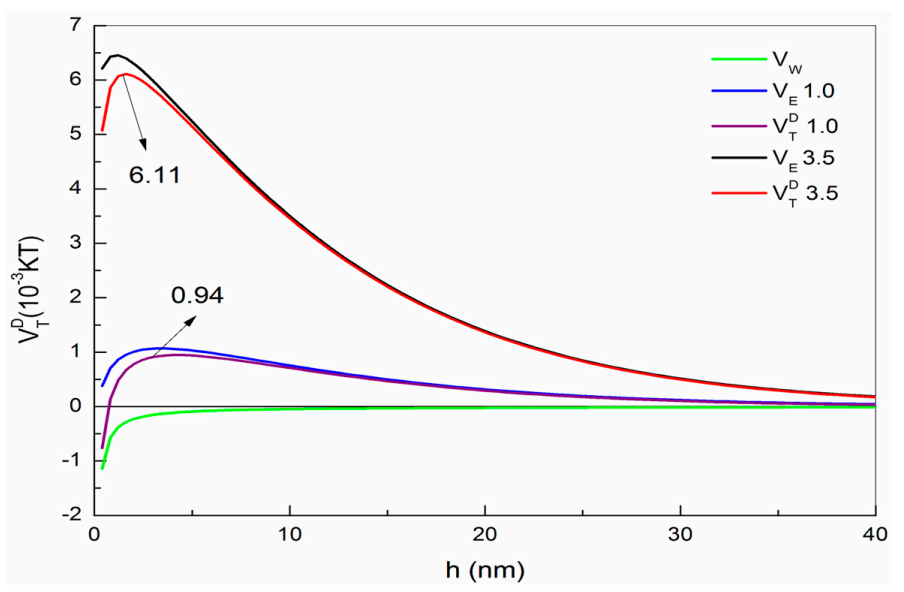

Figure 14. The interaction energy of fluorite and quartz particles with addition of WG with different modulus $\left(c(W G)=5 \times 10^{-5} \mathrm{~mol} / \mathrm{L}, \mathrm{pH}=7\right)$ as a function of particle distance.

\section{Conclusions}

Given the aforementioned results, we arrived at the following primary conclusions:

(1) Fluorite readily floats but quartz does not float using sodium oleate as collector;

(2) There exists strong hetero-coagulation between fine fluorite and quartz which decreases the flotation selectivity to a large extent;

(3) The addition of water glass helps to depress the hetero-coagulation and then improves the separation efficiency in flotation of mixed binary minerals;

(4) Water glass with higher modulus eliminates the hetero-coagulation more thoroughly through increasing the energy barrier between fine fluorite and quartz.

At the same time, the actual flotation tests on fluorite-quartz ore showed that the grade of fluorite can increase from $19.26 \%$ to $25.99 \%$ with increasing the WG modulus from 1.0 to 3.5 in the absence of other flotation reagents, which indicated that conclusions can apply to the industrial application in the flotation of fluorite and quartz ore. The future direction of the researches would focus on how to eliminate the hetero-coagulation to the maximum, for example, adding metal ion into water glass and developing new depressants.

Acknowledgments: This work was financially supported by the Major State Basic Research Development Program of China (973 Program), the Innovation Driven Plan of Central South University (Grant No. 2015CX005), and the Collaborative Innovation Center for Clean and Efficient Utilization of Strategic Metal Mineral Resources.

Author Contributions: Wei Chen designed the experiment; Yawen Gao and Dezhi Liu performed the experiments, collected all the data and wrote this paper. Guofan Zhang analyzed the data and involved in the discussion of the results and approved reading the manuscript.

Conflicts of Interest: The authors declare no conflict of interest.

\section{References}

1. Beger, J.; Schmidt, C.; Szymanowskib, J.; Barhoum, R. Surface activity and fluorite flotation with myristic acid derivatives containing oxygen and sulphur atoms. Colloids Surf. A Physicochem. Eng. Asp. 1993, 80, 197-201. [CrossRef] 
2. Zhang, Y.; Song, S. Beneficiation of fluorite by flotation in a new chemical scheme. Miner. Eng. 2003, 16, 597-600. [CrossRef]

3. Free, M.L.; Miller, J.D. The significance of collector colloid adsorption phenomena in the fluorite/oleate flotation system as revealed by FTIR/IRS and solution chemistry analysis. Int. J. Miner. Process. 1996, 48, 197-216. [CrossRef]

4. Fa, K.; Nguyen, A.V.; Miller, J.D. Interaction of calcium dioleate collector colloids with calcite and fluorite surfaces as revealed by AFM force measurements and molecular dynamics simulation. Int. J. Miner. Process. 2006, 81, 166-177. [CrossRef]

5. Schubert, H.; Baldauf, H.; Kramer, W.; Schoenherr, J. Further development of fluorite flotation from ores containing higher calcite contents with oleoylsarcosine as collector. Int. J. Miner. Process. 1990, 30, 185-193. [CrossRef]

6. Irannajad, M.; Ejtemaei, M.; Gharabaghi, M. The effect of reagents on selective flotation of smithsonite-calcite-quartz. Miner. Eng. 2009, 22, 766-771. [CrossRef]

7. Zhou, W.; Moreno, J.; Torres, R.; Valle, H.; Song, S. Flotation of fluorite from ores by using acidized water glass as depressant. Miner. Eng. 2013, 45, 142-145. [CrossRef]

8. Zhu, Y.; Zhu, J. Chemical Principle of Flotation Regents; Central South University of Technology Press: Changsha, China, 1996.

9. Nordström, J.; Sundblom, A.; Jensen, G.V.; Pedersen, J.S.; Palmqvist, A.; Matic, A. Silica/alkali ratio dependence of the microscopic structure of sodium silicate solutions. J. Colloid Interface Sci. 2013, 397, 9-17. [CrossRef] [PubMed]

10. Arantes, R.S.; Lima, R.M.F. Influence of sodium silicate modulus on iron ore flotation with sodium oleate. Int. J. Miner. Process. 2013, 125, 157-160. [CrossRef]

11. Zhang, G.F.; Cui, M.M.; Zhu, Y.G.; Shi, Q.; Luo, N. Effect of water glass on flotation separation of smithsonite and quartz. Chin. J. Nonferr. Met. 2012, 22, 3535-3540.

12. Al-Thyabat, S. Empirical evaluation of the role of sodium silicate on the separation of silica from Jordanian siliceous phosphate. Sep. Purif. Technol. 2009, 67, 289-294. [CrossRef]

13. Ou, L.M.; Huang, S.J.; Zhu, Y.G. Influence of metal ions on floatability of quartz in flotation of sulfide ores. J. Cent. South Univ. Sci. Technol. 2012, 43, 3-7.

14. Kou, J.; Xu, S.; Sun, T.; Sun, C.; Guo, Y.; Wang, C. A study of sodium oleate adsorption on Ca ${ }^{2+}$ activated quartz surface using quartz crystal microbalance with dissipation. Int. J. Miner. Process. 2016, 154, $24-34$. [CrossRef]

15. Fornasiero, D.; Ralston, J. Cu(II) and Ni(II) activation in the flotation of quartz, lizardite and chlorite. Int. J. Miner. Process. 2005, 76, 75-81. [CrossRef]

16. GÜler, T.; Akdemir, Ü. Statistical evaluation of flotation and entrainment behavior of an artificial ore. Trans. Nonferr. Met. Soc. China 2012, 22, 199-205. [CrossRef]

17. Gong, J.; Peng, Y.; Bouajila, A.; Ourriban, M.; Yeung, A.; Liu, Q. Reducing quartz gangue entrainment in sulphide ore flotation by high molecular weight polyethylene oxide. Int. J. Miner. Process. 2010, 97, 44-51. [CrossRef]

18. Kirjavainen, V.M. Review and analysis of factors controlling the mechanical flotation of gangue minerals. Int. J. Miner. Process. 1996, 46, 21-34. [CrossRef]

19. Cruz, N.; Peng, Y. Rheology measurements for flotation slurries with high clay contents-A critical review. Miner. Eng. 2016, 98, 137-150. [CrossRef]

20. Liang, L.; Peng, Y.; Tan, J.; Xie, G. A review of the modern characterization techniques for flocs in mineral processing. Miner. Eng. 2015, 84, 130-144. [CrossRef]

21. Zhang, W.; Honaker, R.; Li, Y.; Chen, J. The importance of mechanical scrubbing in magnetite-concentrate reverse-flotation. Miner. Eng. 2014, 69, 133-136. [CrossRef]

(C) 2017 by the authors. Licensee MDPI, Basel, Switzerland. This article is an open access article distributed under the terms and conditions of the Creative Commons Attribution (CC BY) license (http:/ / creativecommons.org/licenses/by/4.0/). 